\title{
APLIKASI FUZZY MODEL TAHANI DALAM PENENTUAN PEMILIHAN SPESIFIKASI TABLET PC
}

\author{
I Putu Agus Darmawan Darma Yadnya ${ }^{1 \S}$, G.K. Gandhiadi², Luh Putu Ida Harini ${ }^{3}$ \\ ${ }^{1}$ Jurusan Matematika, Fakultas MIPA - Universitas Udayana [Email: agus.darmawand21 @ gmail.com] \\ ${ }^{2}$ Jurusan Matematika, Fakultas MIPA - Universitas Udayana [Email: gandhiadi@unud.ac.id] \\ ${ }^{3}$ Jurusan Matematika, Fakultas MIPA - Universitas Udayana [Email: ballidah@unud.ac.id] \\ ${ }^{\S}$ Corresponding Author
}

\begin{abstract}
This study aimed to build a fuzzy database system of Tahani model in determining Tablet specification choices according to certain criterias that was inputted by user. The application of Tahani fuzzy model was developed by using PHP as the programming language and MySQL as database storage. The first step in developing this model was determining the input variables that were used in data searching process. After data had been inputted and the user had been choosing certain criteria, the membership degrees which were used in Tablet searching then would be calculated. The outcome of the search showed a list of Tablet which had a recommendation values greater than 0 . It can be concluded that the system had been able to show the recommendation value in accordance of the inputted criterias.
\end{abstract}

Keywords: Tahani model, fuzzy application, Tablet PC, membership degree, recommendation value

\section{PENDAHULUAN}

Perkembangan komputer saat ini lebih mendasarkan pada ukuran dan kualitas. Hal inilah yang membuat para produsen komputer semakin berinovasi untuk membuat karyanya, sehingga ditemukanlah Tablet PC. Tablet PC atau yang dikenal dengan nama Tablet dirancang secara khusus lebih fleksibel dari komputer desktop dan laptop, karena memiliki ukuran kecil sehingga mudah digunakan dimanapun dan kapanpun. Membeli sebuah tablet memang bukan suatu perkara mudah. Banyak konsumen merasa kebingungan dalam membeli tablet karena terkadang tidak dapat memberikan spesifikasi tablet yang jelas sesuai kriteriakriteria yang mereka inginkan. Untuk itu dibutuhkan suatu aplikasi yang dapat membantu konsumen menentukan keputusan dalam memilih tablet sesuai yang mereka inginkan dengan menggunakan logika fuzzy.

Mengenai pemilihan spesifikasi tablet, banyak metode maupun teknik dalam logika fuzzy yang dapat digunakan. Salah satu metode yang dapat digunakan adalah basisdata fuzzy model tahani. Basisdata fuzzy model Tahani masih menggunakan relasi standar, hanya saja model Tahani menggunakan konsep himpunan fuzzy untuk memperoleh informasi pada querynya (Kusumadewi \& Purnomo, 2010). Metode ini menggunakan nilai fire strength dalam menentukan pilihan tablet sesuai kriteria yang diinputkan pengguna (Arisandi, et al.,2016). Hasil yang ditampilkan pada tabel pencarian tablet adalah data tablet yang mendekati kriteria pencarian tablet dengan urutan $\alpha$-predikat atau fire strength terbesar sampai $\alpha$-predikat atau fire strength terkecil (Hamdani, et al., 2011).

Aplikasi fuzzy model Tahani yang dikembangkan akan digunakan untuk menentukan rekomendasi tablet sesuai dengan kriteria-kriteria tablet yang diinputkan pengguna. Kriteria tablet yang digunakan pada penelitian ini adalah memory internal, processor, layar LCD, berat, memory RAM, kamera, dan harga. 


\section{METODE PENELITIAN}

Jenis data yang digunakan dalam penelitian ini adalah data sekunder. Data yang digunakan adalah data spesifikasi tablet yang meliputi memory internal, processor, layar LCD, berat, memory RAM, kamera, dan harga tablet pada bulan Januari sampai Februari 2017. Data ini diperoleh dari Sedhana Jaya Computer yang bertempat di Jl. Diponegoro No 136 Denpasar, Bali.

Pada penelitian ini metode yang digunakan adalah metode basisdata fuzzy model Tahani. Adapun langkah-langkah analisis data yang akan dilakukan adalah

1. Menentukan variabel input awal dari basisdata fuzzy yaitu variabel input fuzzy dan input crisp.

2. Menentukan himpunan fuzzy yang akan digunakan dalam proses pencarian data pada masing-masing variabel input fuzzy yang ditentukan.

3. Menentukan pemodelan proses menggunakan Data Flow Diagram (DFD).

4. Menentukan rancangan basisdata yang yang digunakan.

5. Menentukan fungsi keanggotaan yang digunakan. Fungsi keanggotaan yang digunakan pada penelitian ini adalah representasi kurva bentuk bahu.

6. Menghitung derajat keanggotaan suatu data pada masing- masing variabel fuzzy.

7. Menentukan aturan fuzzy yang digunakan.

8. Menghitung nilai fire strength sesuai dengan kriteria dan operator yang diinputkan pengguna.

9. Pembentukan query berdasarkan jumlah kriteria yang diinputkan pengguna.

10.Hasil pencarian tablet yang ditampilkan adalah data tablet yang memiliki nilai rekomendasi lebih dari 0 , dan data tablet diurutkan dari nilai fire strength terbesar sampai dengan nilai fire strength terkecil.

\section{HASIL DAN PEMBAHASAN}

Variabel-variabel yang akan diteliti pada penelitian ini adalah variabel input dan variabel output. Variabel input dibagi menjadi 2 yaitu variabel input fuzzy dan variabel input crisp. Variabel input fuzzy terdiri dari data-data tablet yang menyangkut memory internal, processor, layar LCD, berat, memory RAM, kamera dan harga. Sedangkan variabel input crisp terdiri dari data-data tablet yang menyangkut ada tidaknya fasilitas seperti 4G, Bluetooth, GPS, dan wi-fi. Variabel output sistem pada penelitian ini berupa rekomendasi tablet sesuai dengan kriteria yang diinginkan pengguna.

\section{Fungsi Keanggotaan}

Pada perancangan fungsi keanggotaan ini terdapat 7 grafik fungsi keanggotaan pada 7 variabel fuzzy yang digunakan yaitu memory internal, processor, layar LCD, berat, memory RAM dan harga. Pada setiap variabel fuzzy memiliki 3 himpunan fuzzy yang melekat pada masing-masing variabel fuzzy.

Himpunan fuzzy pada penelitian ini menggunakan representasi kurva segitiga dan representasi kurva bentuk bahu pada masing masing grafik fungsi keanggotaannya. Domain pada himpunan fuzzy diperoleh dari data terendah, kuartil bawah, median, kuartil atas, dan data tertinggi pada setiap variabel fuzzy. Sebelum mencari nila kuartil bawah, median dan kuartil atas, data akan diurutkan terlebih dahulu dari data terkecil ke data terbesar.

\section{Fungsi Keanggotaan Variabel Memory} Internal

Adapun fungsi keanggotaan pada variabel memory internal adalah sebagai berikut:

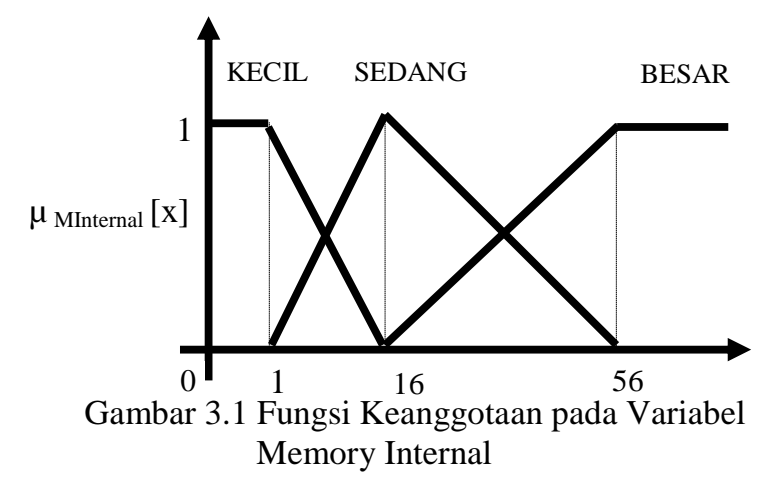


dengan persamaan:

$\mu_{\text {MIntertnalKecil }}[x]=\left\{\begin{aligned} 1 ; & x \leq 10 \\ \frac{16-x}{6} ; & 10<x \leq 16 \\ 0 ; & x>16\end{aligned}\right.$

$\mu_{\text {MInternalsedang }}[x]=\left\{\begin{array}{c}0 ; \quad x \leq 10 \text { atau } x \geq 56 \\ \frac{x-10}{6} ; \quad 10<x \leq 16 \\ \frac{56-x}{40} ; 16<x<56\end{array}\right.$

$\mu_{\text {MInternalBesar }}[x]=\left\{\begin{aligned} 0 ; & x \leq 16 \\ \frac{x-16}{40} ; & 16<x \leq 56 \\ 1 ; & x>56\end{aligned}\right.$

2. Fungsi Keanggotaan Variabel Processor Adapun fungsi keanggotaan pada variabel processor adalah sebagai berikut:

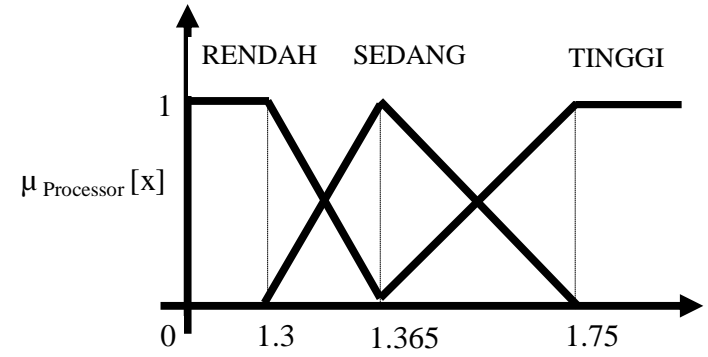

Gambar 3.2 Fungsi Keanggotaan pada Variabel Processor

dengan persamaan:

$\mu_{\text {ProcessorRendah }}[x]=\left\{\begin{array}{c}1 ; x \leq 1.3 \\ \frac{1.365-x}{0.065 ;} 1.3<x \leq 1.365 \\ 0 ; x>1.365\end{array}\right.$

$\mu_{\text {Processorsedang }}[x]$

$$
=\left\{\begin{aligned}
& 0 ; x \leq 1.3 \text { atau } x \geq 1.75 \\
& \frac{x-1.3}{0.065} ; 1.3<x \leq 1.365 \\
& \frac{1.75-x}{0.385} ; 1.365<x<1.75
\end{aligned}\right.
$$

$\mu_{\text {ProcessorTinggi }}[x]=\left\{\begin{aligned} 0 ; & x \leq 1.365 \\ \frac{x-1.365}{0.385 ;} & 1.365<x \leq 1.75 \\ 1 ; & x>1.75\end{aligned}\right.$

3. Fungsi Keanggotaan Variabel Layar LCD Adapun fungsi keanggotaan pada variabel LCD adalah sebagai berikut:

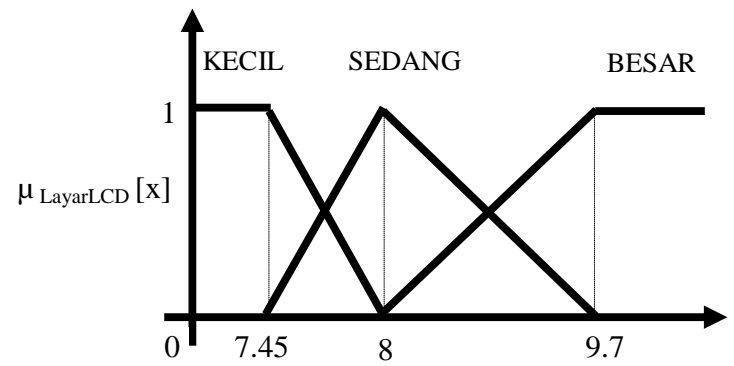

Gambar 3.3 Fungsi Keanggotaan pada Variabel Layar LCD dengan persamaan:

$\mu_{\text {LayarLCDKecil }}[x]=\left\{\begin{aligned} 1 ; & x \leq 7.45 \\ \frac{8-x}{0.55} ; & 7.45<x \leq 8 \\ 0 ; & x>8\end{aligned}\right.$

$\mu_{\text {LayarLCDSedang }}[x]=\left\{\begin{aligned} 0 ; & x \leq 7.45 \text { atau } x \geq 9.7 \\ \frac{x-7.45}{0.55} ; & 7.45<x \leq 8 \\ \frac{9.7-x}{1.7} ; & 8<x<9.7\end{aligned}\right.$

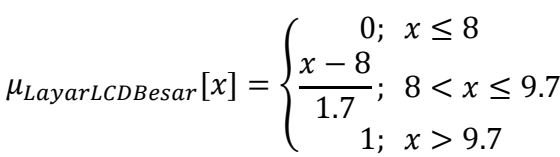

4. Fungsi Keanggotaan Variabel Berat

Adapun fungsi keanggotaan variabel berat adalah sebagai berikut:

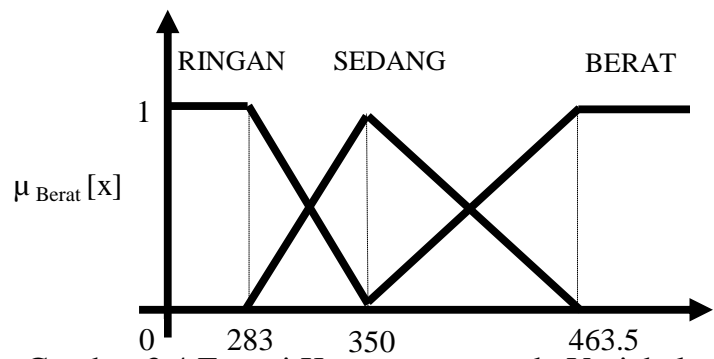

Gambar 3.4 Fungsi Keanggotaan pada Variabel Berat

dengan persamaan:

$$
\begin{aligned}
& \mu_{\text {BeratRingan }}[x]=\left\{\begin{aligned}
1 ; & x \leq 283 \\
\frac{350-x}{67} ; & 283<x \leq 350 \\
0 ; & x>350
\end{aligned}\right. \\
& \mu_{\text {Beratsedang }}[x]=\left\{\begin{aligned}
\frac{x-283}{67} ; & x \leq 283 \text { atau } x \geq 463.5 \\
\frac{463.5-x}{113.5} ; & 350<x<463.5
\end{aligned}\right. \\
& \mu_{\text {BeratBerat }}[x]=\left\{\begin{aligned}
0 ; & x \leq 350 \\
\frac{x-350}{113.5 ;} & 350<x \leq 463.5 \\
1 ; & x>463.5
\end{aligned}\right.
\end{aligned}
$$

5. Fungsi Keanggotaan Variabel Memory RAM Adapun fungsi keanggotaan pada variabel memory RAM adalah sebagai berikut:

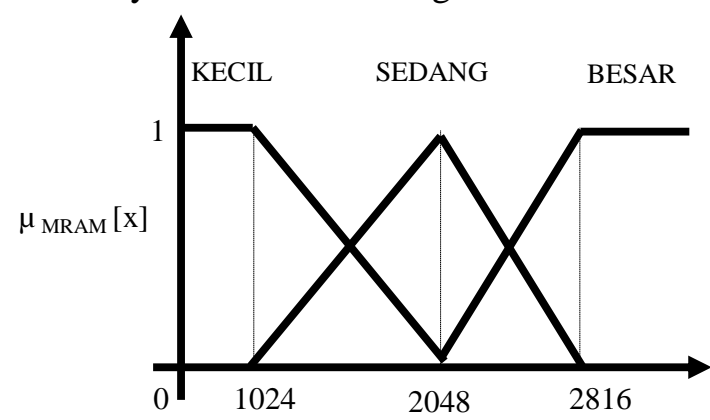

Gambar 3.5 Fungsi Keanggotaan pada Variabel Memory RAM 
dengan persamaan:

$$
\begin{aligned}
& \mu_{\text {MRAMKecil }}[x]=\left\{\begin{aligned}
1 ; & x \leq 1024 \\
\frac{2048-x}{1024} ; & 1024<x \leq 2048 \\
0 ; & x>2048
\end{aligned}\right. \\
& \mu_{\text {MRAMSedang }}[x]=\left\{\begin{aligned}
0 ; & x \leq 1024 \text { atau } x \geq 2816 \\
\frac{x-1024}{1024} ; & 1024<x \leq 2048
\end{aligned}\right.
\end{aligned}
$$$$
\mu_{\text {MRAMBesar }}[x]=\left\{\begin{aligned}
0 ; & x \leq 2048 \\
\frac{x-2048}{768 ;} & 2048<x \leq 2816 \\
1 ; & x>2816
\end{aligned}\right.
$$

6. Fungsi Keanggotaan Variabel Kamera Adapun fungsi keanggotaan pada variabel kamera adalah sebagai berikut:

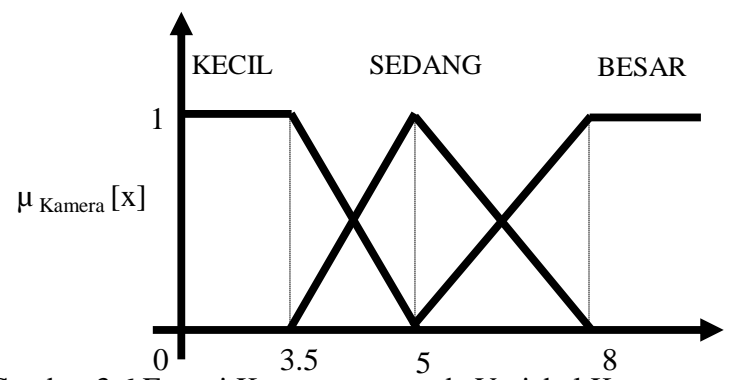

Gambar 3.6 Fungsi Keanggotaan pada Variabel Kamera

dengan persamaan:

$\mu_{\text {KameraKecil }}[x]=\left\{\begin{aligned} 1 ; & x \leq 3.5 \\ \frac{5-x}{1.5} ; & 3.5<x \leq 5 \\ 0 ; & x>5\end{aligned}\right.$

$\mu_{\text {Kamerasedang }}[x]=\left\{\begin{aligned} 0 ; & x \leq 3.5 \text { atau } x \geq 8 \\ \frac{x-3.5}{1.5} ; & 3.5<x \leq 5 \\ \frac{8-x}{3} ; & 5<x<8\end{aligned}\right.$

$\mu_{\text {KameraBesar }}[x]=\left\{\begin{aligned} 0 ; & x \leq 5 \\ \frac{x-5}{3} ; & 5<x \leq 8 \\ 1 ; & x>8\end{aligned}\right.$

7. Fungsi Keanggotaan Variabel Harga Adapun fungsi keanggotaan variabel harga adalah sebagai berikut:

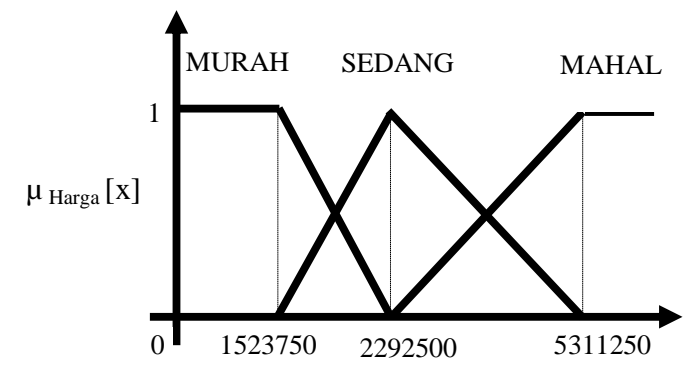

Gambar 3.7 Fungsi Keanggotaan pada Variabel Harga dengan persamaan:

$$
\begin{aligned}
& \mu_{\text {HargamURAH }}[x] \\
& =\left\{\begin{aligned}
\frac{2292500-x}{768750} ; & 1523750<x \leq 2292500 \\
0 ; & x>2292500
\end{aligned}\right. \\
& \mu_{\text {HargaSEDANG }[x]} 0 ; x \leq 1523750 \text { atau } x \geq 5311250 \\
& =\left\{\begin{aligned}
\frac{x-1523750}{768750} ; & 1523750<x \leq 2292500 \\
\frac{5311250-x}{3018750} ; & 2292500<x<5311250
\end{aligned}\right.
\end{aligned}
$$$$
\begin{aligned}
& \mu_{\text {HargamaHAL }}[x] \\
& =\left\{\begin{aligned}
0 ; & x \leq 2292500 \\
\frac{x-2292500}{3018750 ;} & 2292500<x \leq 5311250 \\
1 ; & x>5311250
\end{aligned}\right.
\end{aligned}
$$

\section{Aturan Fuzzy}

Aturan fuzzy yang digunakan pada penelitian ini adalah metode penalaran secara monoton. Aturan fuzzy yang akan digunakan dapat dikelompokkan berdasarkan jumlah kriteria yang diinputkan pengguna ke dalam sistem. Sebagai contoh akan disimulasikan data tablet Samsung Galaxy Tab S dengan nilai variabel fuzzy dari tablet tersebut sebagai berikut:

- Memory Internal : $16 \mathrm{~GB}$

- Processor : $1.9 \mathrm{GHz}$

- Layar LCD : 8.4 Inch

- Berat : $294 \mathrm{gr}$

- Memory RAM : $3072 \mathrm{MB}$

- Kamera : $8.0 \mathrm{MP}$

- Harga : Rp 5.170.000

Setelah mengetahui nilai variabel fuzzy data tablet tersebut maka akan dicari derajat keanggotaan setiap variabel fuzzy yang diketahui. Adapun penghitungan manual pada masing-masing variabel fuzzy adalah sebagai berikut:

a. Derajat Keanggotaan variabel memory Internal

$$
\begin{aligned}
& \mu_{\text {MInternalKecil }}[16]=0 \\
& \mu_{\text {MInternalsedang }}[16]=\frac{16-10}{6}=1 \\
& \mu_{\text {MInternalBesar }}[16]=0
\end{aligned}
$$

b. Derajat keanggotaan variabel processor

$$
\begin{aligned}
& \mu_{\text {ProcessorRendah }}[1.9]=0 \\
& \mu_{\text {ProcessorSedang }}[1.9]=0 \\
& \mu_{\text {ProcessorTinggi }}[1.9]=1
\end{aligned}
$$


c. Derajat keanggotaan variabel layar LCD

$\mu_{\text {LayarLCDKecil }}[8.4]=0$

$\mu_{\text {LayarLCDSedang }}[8.4]=\frac{9.7-8.4}{1.7}=0.7647$

$\mu_{\text {LayarLCDBesar }}[8.4]=\frac{8.4-8}{1.7}=0.2353$

d. Derajat keanggotaan variabel berat

$$
\begin{aligned}
& \mu_{\text {BeratRingan }}[294]=\frac{350-294}{67}=0.8358 \\
& \mu_{\text {BeratSedang }}[294]=\frac{294-283}{67}=0.1642 \\
& \mu_{\text {BeratBerat }}[294]=0
\end{aligned}
$$

e. Derajat keanggotaan variabel memory RAM

$$
\begin{aligned}
& \mu_{\text {MRAMKecil }}[3072]=0 \\
& \mu_{\text {MRAMSedang }}[3072]=0 \\
& \mu_{\text {MRAMBesar }}[3072]=1
\end{aligned}
$$

f. Derajat keanggotaan variabel kamera

$$
\begin{aligned}
& \mu_{\text {KameraKecil }}[8]=0 \\
& \mu_{\text {KameraSedang }}[8]=0 \\
& \mu_{\text {KameraBesar }}[8]=\frac{8-5}{3}=1
\end{aligned}
$$

g. Derajat keanggotaan variabel harga

$$
\begin{aligned}
\mu_{\text {HargaMurah }}[5170000] & =0 \\
\mu_{\text {Hargasedang }}[5170000] & =\frac{5311250-5170000}{3018750} \\
& =0.0468 \\
\mu_{\text {Hargamahal }}[5170000] & =\frac{5170000-2292500}{3018750} \\
& =0.9532
\end{aligned}
$$

Misalkan pengguna ingin mencari data tablet berdasarkan kriteria layar LCD, maka aturan fuzzy yang diperoleh dari kriteria LCD adalah

- IF Layar LCD Kecil THEN Rekomendasi

- IF Layar LCD Sedang THEN Rekomendasi

- IF Layar LCD Besar THEN Rekomendasi

Nilai rekomendasi untuk pencarian tablet berdasarkan kriteria layar LCD diperoleh dari derajat keanggotaan variabel layar LCD. Berdasarkan derajat keanggotaan yang diperoleh maka untuk kriteria layar LCD Kecil memilki nilai rekomendasi 0 , kriteria layar LCD Sedang memiliki nilai rekomendasi 0.7647 , dan kriteria layar LCD Besar memiliki nilai rekomendasi 0,2353.

\section{Aturan Fuzzy untuk 2 Kriteria Pilihan}

Misalkan pengguna ingin mencari data tablet dengan kriteria layar LCD Sedang dan kapasitas memory internal Sedang. Maka aturan fuzzy yang dapat dibentuk dari 2 kriteria tersebut adalah:

- IF Layar LCD Sedang AND Memory Internal Sedang THEN Rekomendasi

Penghitungan nilai fire strength untuk aturan fuzzy kriteria layar LCD Sedang dan memory internal Sedang adalah sebagai berikut:

$$
\begin{aligned}
& \mu_{(\text {LayarLCDSEDANG } \cap \text { MInternalSEDANG })} \\
& \quad=\min \left(\mu_{\text {LayarLCDSEDANG }}, \mu_{\text {MInternalSEDANG }}\right) \\
& \quad=\min (0.7647,1) \\
& \quad=0.7647
\end{aligned}
$$

Nilai rekomendasi merupakan fire strength dari (Layar LCD Sedang) dan (Memory Internal Sedang). Berdasarkan fire strength yang diperoleh, maka nilai rekomendasi untuk kriteria layar LCD Sedang dan memory internal Sedang adalah 0.7647 .

\section{Aturan Fuzzy untuk 3 Kriteria pilihan}

Misalkan pengguna ingin mencari data tablet dengan layar LCD Sedang dan kapasitas memory internal sedang dan kecepatan processornya Tinggi. Maka aturan fuzzy yang dapat dibentuk dari 3 kriteria tersebut adalah sebagai berikut:

- IF Layar LCD Sedang AND Memory Internal Sedang AND Processor Tinggi THEN Rekomendasi

Penghitungan nilai fire strength untuk aturan fuzzy kriteria layar LCD Sedang dan memory internal Sedang dan processor Tinggi adalah sebagai berikut:

$$
\begin{aligned}
& \mu_{\text {LayarLCDSEDANG }} \cap \text { MInternalSEDANG } \cap \text { ProcessortINGGI } \\
& =\min \left(\min \left(\mu_{\text {LayarLCDSEDANG }}, \mu_{\text {MInternalSEDANG }}\right)\right. \\
& \left.\quad, \mu_{\text {ProcessorTINGGI }}\right) \\
& =\min (\min (0.7647,1), 1) \\
& =\min (0.7647,1) \\
& =0.7647
\end{aligned}
$$

Nilai rekomendasi merupakan fire strength dari (Layar LCD Sedang) dan (Memory Internal Sedang) dan (Processor Tinggi). Berdasarkan 
nilai fire strength yang diperoleh, maka nilai rekomendasi dari kriteria layar LCD Sedang dan memory internal Sedang dan processor Tinggi adalah 0.7647 .

\section{Pembentukan Query}

Pembentukan query pada variabel fuzzy ditentukan dari banyaknya kriteria yang dipilih pengguna sehingga query dapat dikelompokkan menjadi 7 query yaitu 1 kriteria, 2 kriteria, 3 kriteria hingga 7 kriteria.

\section{Query dengan 1 Kriteria Pilihan}

Misalkan ingin diketahui Tablet apa saja yang ukuran layar LCD nya Sedang. Query yang dapat dibentuk dengan kriteria ukuran layar LCD SEDANG adalah:

SELECT : a. nama_brand, b.nama_tablet,

b. harga, b.fire_strength 1 ,

c. nama_himpunan, c. da

FROM : a. brand_tablet, b. data_tablet, c. hasil_fuzzy

WHERE $\quad$ ( b. layarlcd $=$ 'SEDANG')AND

(a. id_brand $=$ b. id_brand) AND

(b. id_tablet $=$ c. id_tablet) AND

(b. fire_strength $1>0$ )

ORDER BY: b. fire_strength1, b. harga

Gambar 3.8 memperlihatkan hasil pencarian terhadap kriteria Layar LCD SEDANG.

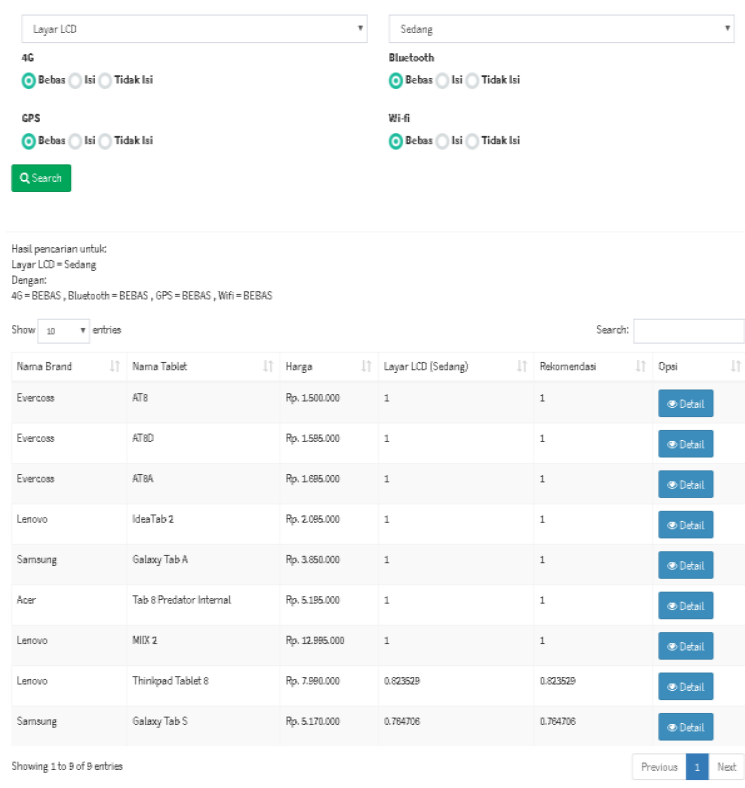

Gambar 3.8 Hasil Pencarian untuk 1 Kriteria Pilihan Nilai rekomendasi pencarian Tablet dengan kriteria layar LCD SEDANG diperoleh dari derajat keanggotaan pada variabel layar LCD pada himpunan fuzzy SEDANG.

\section{Query dengan 2 Kriteria Pilihan}

Misalkan ingin diketahui Tablet apa saja yang ukuran layar LCD nya SEDANG dan kapasitas memory internalnya SEDANG. Query yang dapat dibentuk pada kriteria pilihan layar LCD SEDANG dan memory internal SEDANG adalah
SELECT
: a. nama_brand, b.nama_tablet,
b. harga, b.fire_strength2,
c. nama_himpunan, c. da
FROM : a. brand_tablet, b. data_tablet, c. hasil_fuzzy
WHERE : (b. layarlcd = 'SEDANG')AND
(b. minternal $=$ 'SEDANG')AND
(a. id_brand $=$ b. id_brand) AND
(b. id_tablet $=$ c. id_tablet) AND
(b. fire_strength $2>0$ )

ORDER BY : b. fire_strength2, b. harga

Gambar 3.9 memperlihatkan hasil pencarian dengan nilai fire strength hasil operasi dari (Layar LCD SEDANG) AND (Memory Internal SEDANG) sebagai berikut:

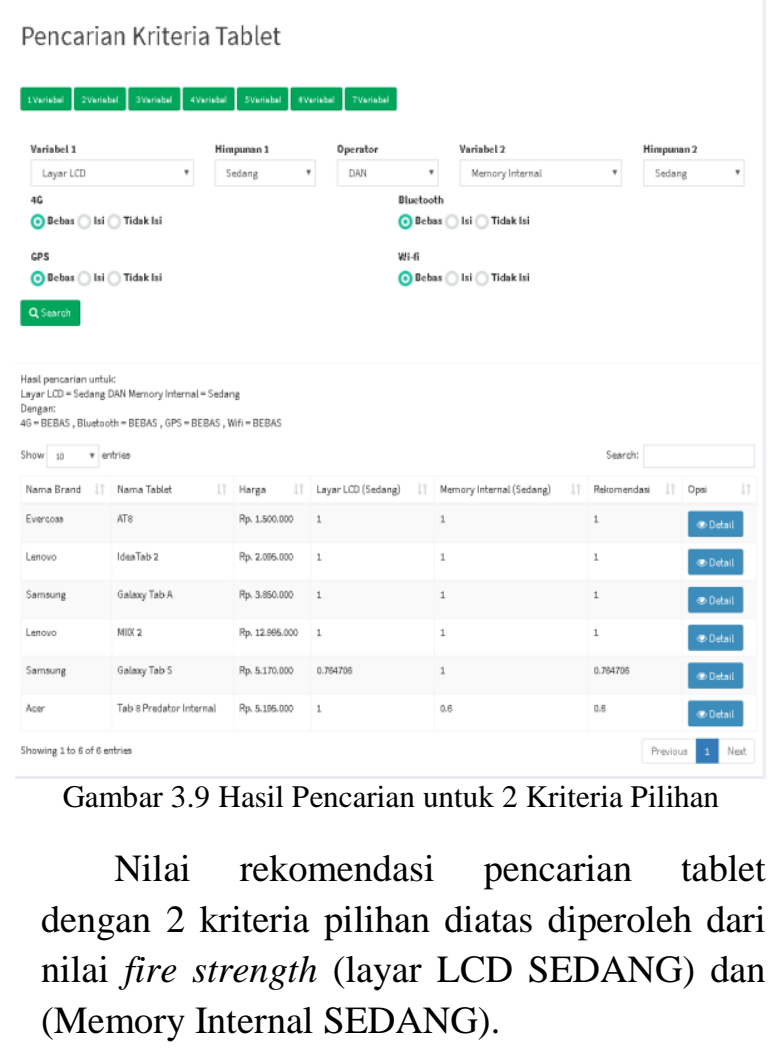




\section{Query dengan 3 Kriteria Pilihan}

Misalkan ingin diketahui Tablet apa saja yang ukuran layarnya SEDANG dan memory internal SEDANG dan kecepatan processornya TINGGI. Query yang dapat dibentuk dari 3 kriteria fuzzy tersebut adalah:

SELECT : a. nama_brand, b.nama_tablet,

b. harga, b.fire_strength3,

c. nama_himpunan, c. da

FROM : a. brand_tablet, b. data_tablet, c. hasil_fuzzy

WHERE : (b. layarlcd = 'SEDANG')AND

(b. minternal $=$ 'SEDANG')AND

(b. processor $=$ 'TINGGI')AND

(a. id_brand $=$ b. id_brand) AND

(b. id_tablet $=$ c. id_tablet) AND

(b. fire_strength $3>0$ )

ORDER BY : b. fire_strength3, b. harga

Gambar 3.10 memperlihatkan hasil pencarian nilai fire strength operasi dari (Layar LCD SEDANG) AND (Memory Internal SEDANG) AND (Processor TINGGI) sebagai berikut:

Pencarian Kriteria Tablet

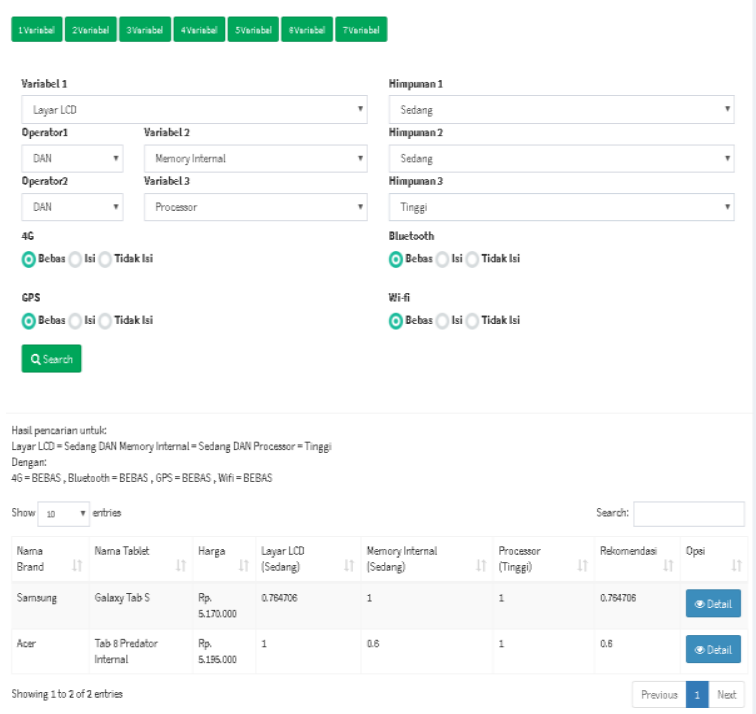

Gambar 3.10 Hasil Pencarian untuk 3 Kriteria Pilihan

Nilai rekomendasi pencarian Tablet dengan 3 kriteria diatas diperoleh dari nilai fire strength (Layar LCD SEDANG) dan (Memory Internal SEDANG) dan (Processor TINGGI).

\section{KESIMPULAN DAN SARAN}

Berdasarkan hasil dan pembahasan yang telah dipaparkan sebelumnya, maka dapat disimpulkan bahwa data tablet yang disimulasikan yaitu Tablet Samsung Galaxy Tab S memiliki nilai rekomendasi sebesar 0.7647 dengan kriteria Layar LCD Sedang dan Memory Internal Sedang dan Processor Tinggi yang ditampilkan pada tabel pencarian tablet sesuai dengan penghitungan nilai fire strength yang dilakukan secara manual. Sehingga hasil rancangan aplikasi fuzzy model Tahani telah mampu menghasilkan rekomendasi sesuai dengan kriteria yang diinputkan pengguna.

Adapun saran yang dapat disampaikan untuk penelitian selanjutnya adalah dengan mengganti fungsi keanggotaan dengan fungsi keanggotaan yang sesuai dengan persepsi masyarakat tentang barang yang ingin diteliti. Dan membuat kriteria yang bisa dikurangi atau ditambahkan tergantung kehendak pengguna.

\section{DAFTAR PUSTAKA}

Arisandi, Sarita, I., \& Sagala, H. S. (2016). Sistem Penunjang Keputusan Pemilihan Hotel di Kendari Menggunakan Metode Fuzzy Tahani Berbasis Web. semanTIK, Vol.2, 331-340.

Hamdani, Haviluddin, \& Abdillah, M. S. (2011). Sistem Pendukung Keputusan Pembelian Notebook Menggunakan Logika Fuzzy Tahani. Jurnal Informatika Mulawarman, Vol.6, No.3, 98-104.

Kusumadewi, S., \& Purnomo, H. (2010). Aplikasi Logika Fuzzy untuk Pendukung Keputusan (2nd ed.). Yogyakarta: Graha Ilmu. 